\title{
Smart City: a GECAD-BISITE Energy Management Case Study
}

\author{
Bruno Canizes $^{1}$, Tiago Pinto ${ }^{1,2}$, João Soares ${ }^{1}$, Zita Vale ${ }^{1}$, Pablo Chamoso ${ }^{2}$, Daniel Santos ${ }^{2}$ \\ ${ }^{1}$ GECAD - Research Group on Intelligent Engineering and Computing for Advanced \\ Innovation and Development, Institute of Engineering, Polytechnic of Porto, Portugal \\ \{brmrc, tmcfp, joaps, zav\}@isep.ipp.pt \\ ${ }^{2}$ BISITE Research Centre, University of Salamanca, Salamanca, Spain \\ \{tpinto, chamoso,daniel_santos\}@usal.es

\begin{abstract}
This paper presents the demonstration of an energy resources management approach using a physical smart city model environment. Several factors from the industry, governments and society are creating the demand for smart cities. In this scope, smart grids focus on the jintelligent management of energy resources in a way that the use of energy from renewable sources can be maximized, and that the final consumers can feel the positive effects of less expensive (and pollutant) energy sources, namely in their energy bills. A large amount of work is being developed in the energy resources management domain, but an effective and realistic experimentation are still missing. This work thus presents an innovative means to enable a realistic, physical, experimentation of the impacts of novel energy resource management models, without affecting consumers. This is done by using a physical smart city model, which includes several consumers, generation units, and electric vehicles.
\end{abstract}

Keywords: energy resource management, optimization, physical models, smart cities smart grids.

\section{Introduction}

Smart cities are one of the trending topics in the global research agenda. A smart city concept is the combination of ICT solutions, government policies and society involvement. As defined by the IEEE Smart Cities group a smart city has the following characteristics [1]: a smart economy, smart mobility, a smart environment, smart people, smart living and smart governance. With the increasing population and urbanization, the availability of natural resources will be significant problem. Based on [2], today cities are occupied by $51 \%$ of population, but consume $80 \%$ of the resources. The accelerating growth of cities and their disproportionate consumption of physical and social resources is addressed by the United Nations to be the greatest challenge.

This project has received funding from the European Union's Horizon 2020 research and innovation programme under the Marie Sklodowska-Curie grant agreement No 641794 (project DREAM-GO) and from FEDER Funds through COMPETE program and from National Funds through FCT under the project UID/EEA/00760/2013. Bruno Canizes is supported by FCT Funds through the SFRH/BD/110678/2015 PhD scholarship. 
The European Union (EU) is mostly concerned about the eventual fuel based primary source shortage, and hence the impact of electricity use in the environment is presently taken as very serious at scientific, economic and politic levels [3]. These concerns have led to intensive research and to new energy policies envisaging the increased use of renewable energy sources for electricity production and increased energy use efficiency. The EU has, in fact, assumed a pioneer and leading role in energy matters, namely in what concerns the increase of renewable energy sources. EU as a whole has committed to reach its $20 \%$ renewable energy target for 2020 [4]. Moreover, in 23 October 2014, EU leaders agreed on setting a revised target for increasing the share of renewable based energy to at least $27 \%$ of the EU's energy consumption by 2030 [5]. The EU presents even more ambitious targets for 2050, with the commitment to reduce emissions to $80-95 \%$ below 1990 levels [6].

Such ambitions targets demand that energy resources are managed in a completely different way from what was usual so far. In this scope, the Smart Grid (SG) paradigm arises, as the most commonly accepted solution for this problem [3]. The distributed management approach supported by SG boosts the emergence of seyeral innovative energy resource management approaches. The penetration of a large number of electric vehicles is one of the most important topics in this domain, due to the large dimensionality that it brings to the optimization problem. This problem is usually solved using meta-heuristics, namely with simulated annealing in [7] and with a novel multi-dimensional signaling method, in [8], just to name a few. A solid survey on this theme can be consulted in [9]. The impact of different sources of uncertainty is also broadly explored, such as the work presented in [10]. Although a significant amount of work is being done in this domain, the Yarge majority of the performed studies are conducted solely under simulated environmental settings. This is mostly because SG are still an emerging reality, and thes, practical implementations are still not sufficiently widely spread. Even when considering the real implementations that are available, the execution of innovative experimental studies is difficult, because of the implications on the several users that are present in the real environment.

In order to surpass these hurdles, this paper presents an experimental study of an innovative energy resources management approach, in a smart city environment, using a laboratorial physical model of the city. The considered model is located in a BISITE laboratory, and departs from a previous implementation, done in collaboration with IBM as a product for Vodafone. This model has been developed to show how their real services work. So, different requirements about the communication protocol have been set (MQTT messages with a specific frequency and format) in order to be integrated with their IOC software [11]. These models have already allowed the demonstration of different studies, namely: waste trucks routing optimization, home care, public lighting services, and citizens' active participation. The model has been updated to include energy generation systems like solar panels and wind energy generators, so as to allow being used for the demonstration of energy management resources on the scope of the DREAM-GO project [12], specifically, the work presented in this paper.

After this introductory section, section II presents the proposed energy resources management optimization model. Section III presents the case study using a real model of a Smart City and the results are presented in Section IV. Finally, in Section V, the most relevant conclusions are presented. 


\section{Proposed method}

The prosed method deals with the optimal scheduling of the available resources in a Smart City (SC) context. The optimization model considers the energy sell or buy from the external suppliers or market. The Smart City Operator (SCO) that acts in behalf of its consumers, will sell or buy electrical energy taking into account the available resources. 24 periods of the day-ahead scheduling are used in the proposed method.

Minimize

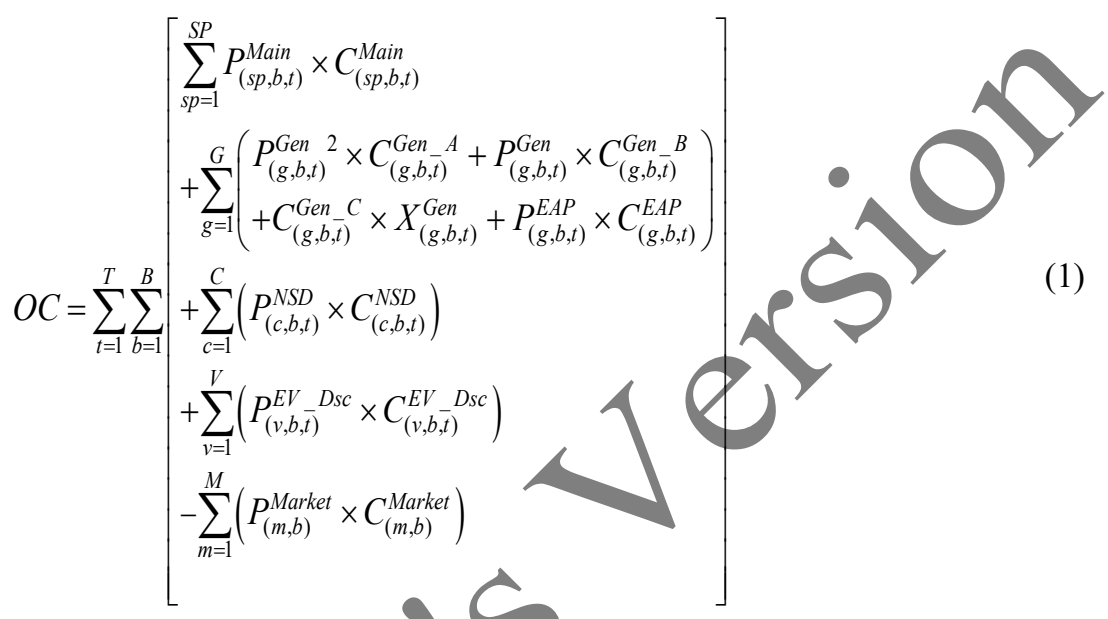

Below it is presented de constraints of the proposed method. Equations (3), (6) and (7) present the EV technical limits for each period $t$. The generation units' limits are described by equations (4) and (5).

\subsection{Equality constraints}

- Power balance in each period $t$ and in each bus $b$.

$$
\begin{array}{ll}
\sum_{s p=1}^{S P} P_{(s p, \bar{b}, t)}^{\text {Main }}+\sum_{g=1}^{G}\left(P_{(g, b, t)}^{G e n}-P_{(g, b, t)}^{E A P}\right) & \\
-\sum_{c=1}^{C}\left(P_{(c, b, t)}^{\text {Demand }}\right)+\sum_{v=1}^{V}\left(P_{(v, b, t)}^{E V \text { Dsc }}-P_{(v, b, t)}^{E V . C h}\right)-\sum_{m=1}^{M} P_{(m, b)}^{\text {Market }}=0 \\
\forall t \in\{1, \ldots, T\} ; \\
\\
\forall b \in\{1, \ldots, B\} ; \\
\\
\forall m \in\{1, \ldots, M\} ;
\end{array}
$$

- $\quad$ EV battery balance determined by the energy remaining from the previous period, the trip demand and charge/discharge in the current period. 


$$
\begin{array}{ll}
E_{(v, b, t)}^{E V}=E_{(v, b, t-1)}^{E V}+P_{(v, b, t)}^{E V_{-} C h} \times \Delta t \times \eta_{C h}- & \\
P_{(v, b, t)}^{E V \_D s c} \times \Delta t \times \frac{1}{\eta_{D c h}}-E_{(v, t)}^{E V-t r i p} & \forall t \in\{1, \ldots, T\} ; \\
& \forall b \in\{1, \ldots, B\} ; \\
& \forall v \in\{1, \ldots, V\}
\end{array}
$$

\subsection{Inequality constraints}

- Generation units limits in each period $t$.

$$
\begin{aligned}
P_{(g, b, t)}^{\text {MinGen }} \leq P_{(g, b, t)}^{G e n} \leq P_{(g, b, t)}^{\text {MaxGen }} & \forall t \in\{1, \ldots, T\} ; \\
& \forall b \in\{1, \ldots, B\} ; \\
& \forall g \in\{1, \ldots, G\}
\end{aligned}
$$

- Main network supplier maximum limit in each period $t$.

$$
\begin{aligned}
P_{(s p, b, t)}^{\text {Main }} \leq P_{(s p, b, t)}^{\text {MaxMain }} & \forall t \in\{1, \ldots, T\} \\
& \forall b \in\{1, \ldots, B\} \\
& \forall s p \in\{1, \ldots, S P\}
\end{aligned}
$$

- Vehicle charge and discharge are not simultaneous.

$$
\begin{aligned}
& X_{(v, b, t)}^{E V}+Y_{(v, b, t)}^{E V} \leq 1 \quad \forall t \in\{1, \ldots, P\} ; \\
& \forall b \in\{1, \ldots, B\} ; \\
& \forall y \in\{1, \ldots, V\} ;
\end{aligned}
$$

- Charge and discharge limit for each storage unit considering the battery charge rate and battery balance.

$$
\begin{aligned}
& P_{(\mathrm{v}, b, t)}^{\mathrm{EV} C h} \leq P_{(\mathrm{v}, b, t)}^{\mathrm{MaxH} \mathrm{V}_{-} C h} \times Y_{(v, b, t)}^{E V}
\end{aligned}
$$

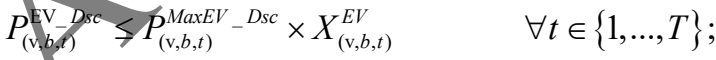

$$
\begin{aligned}
& P_{\left(\mathrm{v}, b_{b}, t\right)}^{\mathrm{EV} D_{s c}} \times \Delta t \leq E_{(\mathrm{v}, b, t-1)}^{E V} \quad \forall b \in\{1, \ldots, B\} \text {; } \\
& P_{(\mathrm{v}, b, t)}^{\mathrm{EV}-C h} \times \Delta t \leq E_{(\mathrm{v}, b)}^{E V}-E_{(\mathrm{v}, b, t-1)}^{E V} \quad \forall s \in\{1, \ldots, \mathrm{V}\}
\end{aligned}
$$

\section{Case study}

The following case study will demonstrate the use of the proposed methodology. The SC have 14 buses as can be seen in the one-line diagram presented in Fig. 1a. Fig. $1 \mathrm{~b}$ shows the real model of the Smart City. The SC distribution power network has 
$15 \mathrm{kV}$ with one feeder. As can be seen the network is completely meshed but radiality operated. The SC has:1 shopping mall - installed power: $1,500 \mathrm{~kW} ; 1$ hospital installed power: $800 \mathrm{~kW}$; 1 fire station - installed power: $600 \mathrm{~kW} ; 15$ individual houses - installed power: $190 \mathrm{~kW} ; 7$ office buildings: installed power: $555 \mathrm{~kW} ; 3 \mathrm{EVs}-2$ cars $(25 \mathrm{~kW}$ each) and 1 waste truck $(250 \mathrm{~kW}) ; 1$ wind farm $(2$ wind generators with $1,000 \mathrm{~kW}$ each); $1 \mathrm{PV}$ power station (2 PV units with $250 \mathrm{~kW}$ each); 1 waste to energy power station $(500 \mathrm{~kW}) ; 1$ power plant (external supplier $-5,000 \mathrm{~kW}) ; 5 \mathrm{PV}$ panels for individual houses (3.68kW each); 7 PV panels for office buildings (11.04kW each).

For the period 1 the two EV cars are located in bus 4 and the waste truck in the bus 3. Table 1 shows the location of each building type in the Smart City.

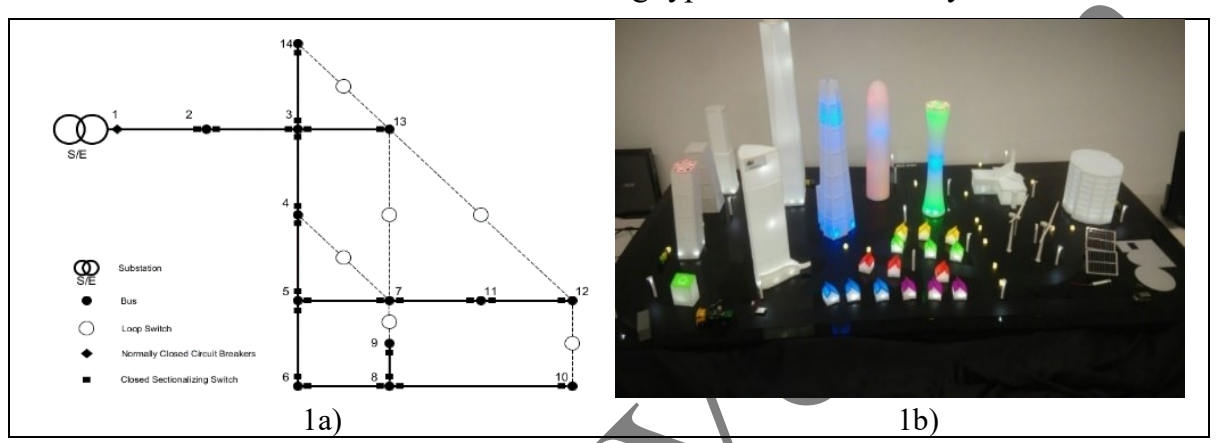

Fig. 1a). Smart City one-line diagram. Fig. 1b. Smart City real model

Table 1. Smart City Building Type Location

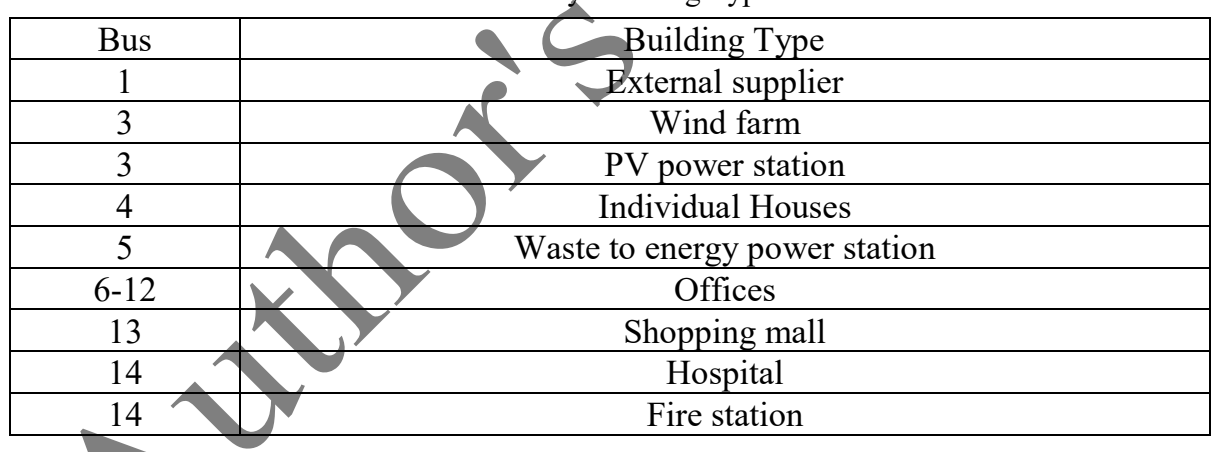

The considered prices are 0.02 m.u. $/ \mathrm{kW}$ for PV, 0.09 m.u. $/ \mathrm{kW}$ for wind power, 0.04 m.u. $/ \mathrm{kW}$ for waste-to-energy power, $0.10 \mathrm{~m} . \mathrm{u} . / \mathrm{kW}$ for the external supplier and 0.15 m.u. $/ \mathrm{kW}$ for $\mathrm{V} 2 \mathrm{G}$ discharge. Charge of $\mathrm{V} 2 \mathrm{G}$ is considered $0.13 \mathrm{~m} . \mathrm{u} . / \mathrm{kW}$. The initial state for vehicles was considered randomly in the beginning of the day.

All loads with exception of the hospital and fire station are allowed to use incentivebased demand response programs, considering a remuneration for customers to reduce their load at maximum until $20 \%$ of the initial load. The incite value is 0.09 m.u. $/ \mathrm{kW}$.

Fig. 2a presents the forecasted power demand for each type of building as well as the solar and wind generation profile in the SC, not considering the EVs load. It can be seen that the peak load is expected at afternoon periods due to the great contribution of shopping mall, hospital and office buildings. Fig. 2b shows the forecasted EVs' trip demand in $\mathrm{kWh}$. The tool presented in [13] was used to generate the scenarios. Most trips occur at due to a great contribution of the waste truck. 
a)

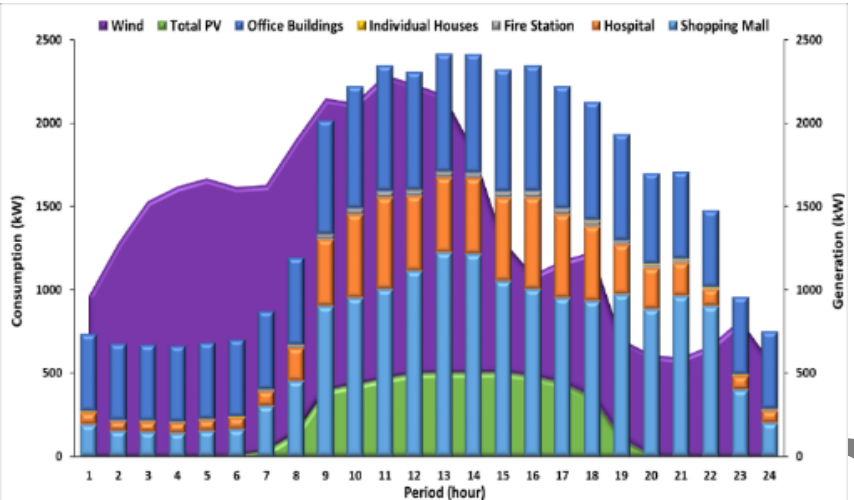

b)

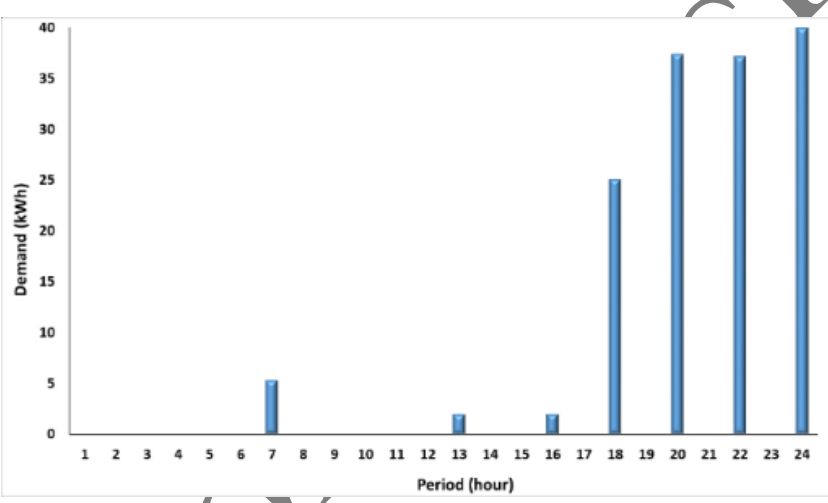

Fig. 2a. Forecasted load consumption (by type), PV and wind power profile. Fig. 2b. Forecast for EVs trip demand

\section{Results}

The optimization method and simulations were performed in MATLAB 2014a 64bit using the TOMLAB software [14]. A computer with one processor Intel Xeon E5$2620 \mathrm{v} 22.10 \mathrm{GHz}$ with twelve cores, $16 \mathrm{~GB}$ of random access memory, and Windows 10 Professional 64-bit operating system was used.

In order to compute the proposed method, the algorithm took around 0.65 seconds. The result of the objective function, i.e., the final cost is 30.12 m.u..

Fig. 3a presents the power supplied by the external supplier and the all distributed generators considered in the case study. It can also be seen the results for the energy sold to the market and the values for the total consumption. It is important to note that the total consumption considers also the EVs charge. These results are for the 24 periods under study. One can see that the external supplier is required at the begging of the afternoon until the night. In these periods the DG power generation decrease and the demand remains higher. Also, it is possible to see that in early morning exists an 
excess of generation. Due to this, the model considered that exist an advantage to sell the remaining power to the market.

As can be seen in Fig. $3 \mathrm{~b}$ the generation by wind power has the higher contribution to supply all the demand. The wind power and waste-to-energy power are supplying in all periods. The main reason is related to their cost when compared with external supplier. Additionally, for the wind power, it is considered having dispatchable power.

a)

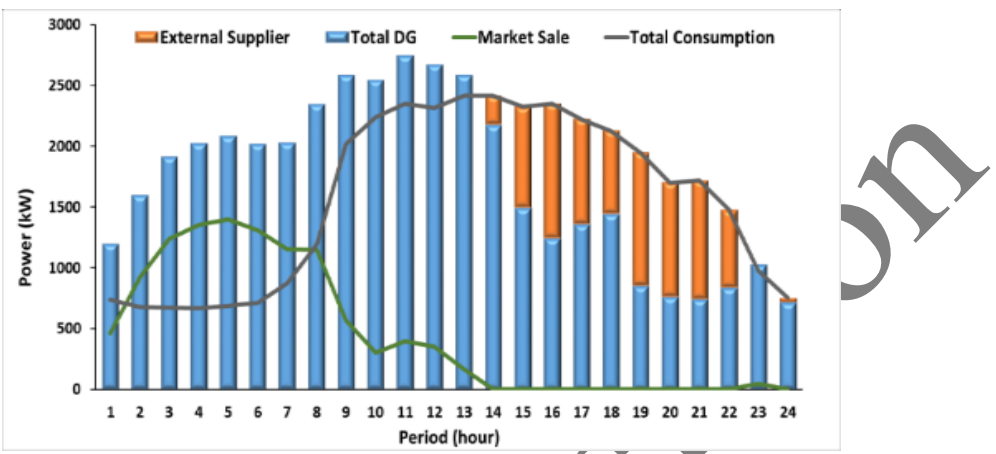

b)

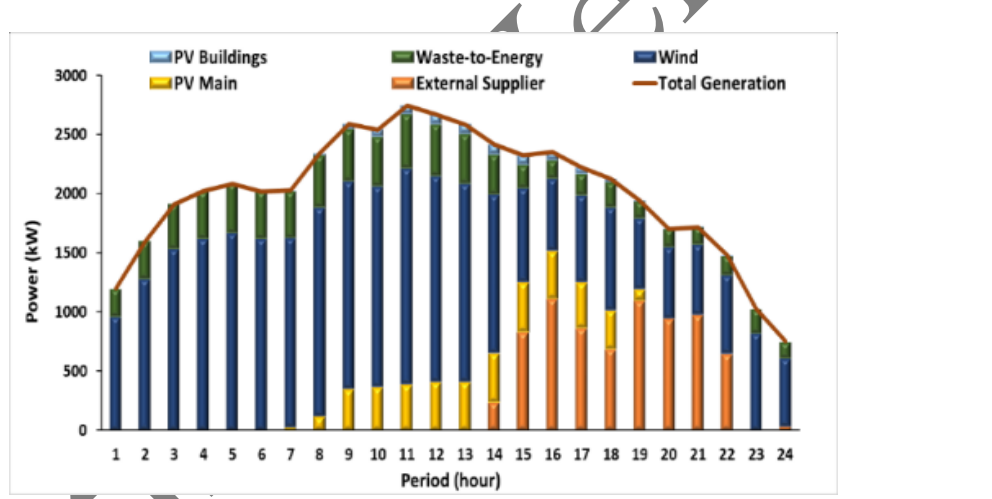

Fig. 3a. Power supplied scheduling. Fig. 3b. Power supplied scheduling by generator type

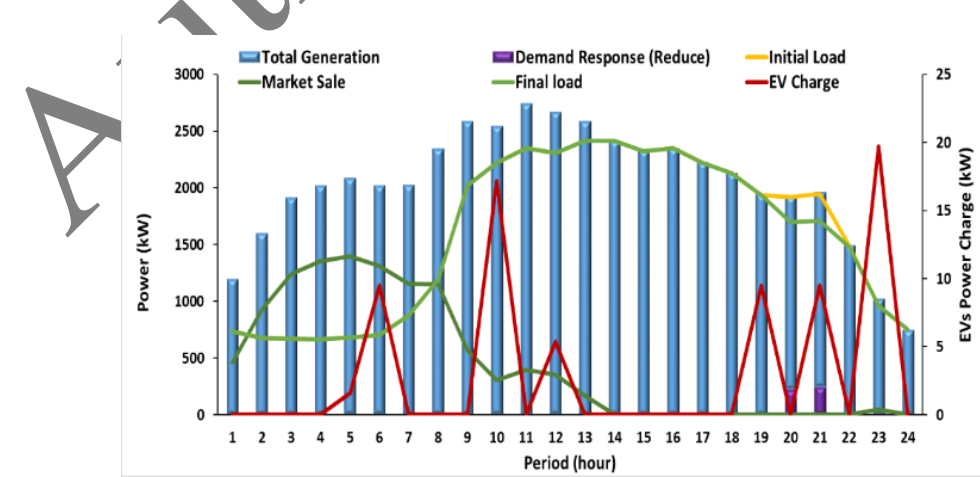

Fig. 4. Demand response and EV scheduling

Fig. 4 depicts the scheduling for demand response (in this case study is was considered only the reduction program) and for EVs. The demand response program is 
verified in periods $20,21,22$. The power reduced by the demand response program in each of those periods are: $220 \mathrm{~kW}, 240.19 \mathrm{~kW}$ and $13.41 \mathrm{~kW}$ respectively. Regarding to EVs scheduling it is only verified the charging and no discharging. It is possible to see in Fig. 4 that the EVs charging occur in periods 5, 6, 10, 12, 19, 21 and 23.

\section{Conclusions}

This paper has presented a resource scheduling management approach applied to a physical smart city model environment. The Smart City Operator can use their resources at their optimal operating point while minimizing operation costs and obtaining more profit taking into account the several constraints associated with their resources and energy suppliers. This can be achieved with adequate resource scheduling algorithms as the method proposed in this paper.

The proposed method proved to be adequate to support the Smart City Operator in the operation field which can lead to operation costs reduction.

\section{References}

1. IEEE Smart Cities group website. Available at: http://smartcities.ieee.org/ [Accessed January 2017].

2. BSi, "The Role of Standards in Smart Cities", Available at: http://www.bsigroup.com/LocalFiles/en-GB/smart-cities/resources/The-Role-of-

Standards-in-Smart-Cities-Issue-2-August-2014.pdf [Accessed January 2017].

3. H. Lund, "Renewable Energy Systems, Renewable Energy Systems - A Smart Energy Systems Approach to the Choice and Modeling of 100\% Renewable Solutions", Academic Press, 2nd Edition, 2014.

4. European Commission, "The 2020 climate and energy package", Available at: http://ec.europa.eu/clima/policies/package/index_en.htm, 2009 [Accessed October 2016].

5. European Commission, "2030 framework for climate and energy policies", Available at: http://ec.europa.eu/clima/policies/2030/index_en.htm, 2014 [Accessed October 2016].

6. European Commissign, A Roadmap for moving to a competitive low carbon economy in 2050, Available at: http:/eur-lex.europa.eu/legalcontent/EN/ALL/? $u$ uri=CELEX:52011DC0112R(01), 2011 [Accessed January 2017].

7. Sousa, T. et al., "A hybrid simulated annealing approach to handle energy resource management considering an intensive use of electric vehicles". Energy, 2014, 67, 81-96.

8. J. Søares, et al., "Multi-dimensional signaling method for population-based metaheuristics: Solving the large-scale scheduling problem in smart grids", Swarm and Evolutionary Computation, 2016; 29:13-32

9. M. Iqbal, et al., "Optimization classification, algorithms and tools for renewable energy: A review", Renewable and Sustainable Energy Reviews, 39, pp.640-654, 2014.

10. Conejo, A.J., Carrión, M. \& Morales, J.M., "Decision Making Under Uncertainty in Electricity Markets", Springer US, 2010.

11. BISITE. Available at: http://www-03.ibm.com/software/products/es/intelligent-operationscenter [Accessed January 2017].

12. Dream-go project, Available at: http://www.dream-go.ipp.pt [Accessed January 2017].

13. J. Soares, et al., "Electric vehicle scenario simulator tool for smart grid operators", Energies, 2012, 5(6), 1881-1899.

14. TOMLAB. Available at: http://tomopt.com/tomlab [Accessed January 2017]. 